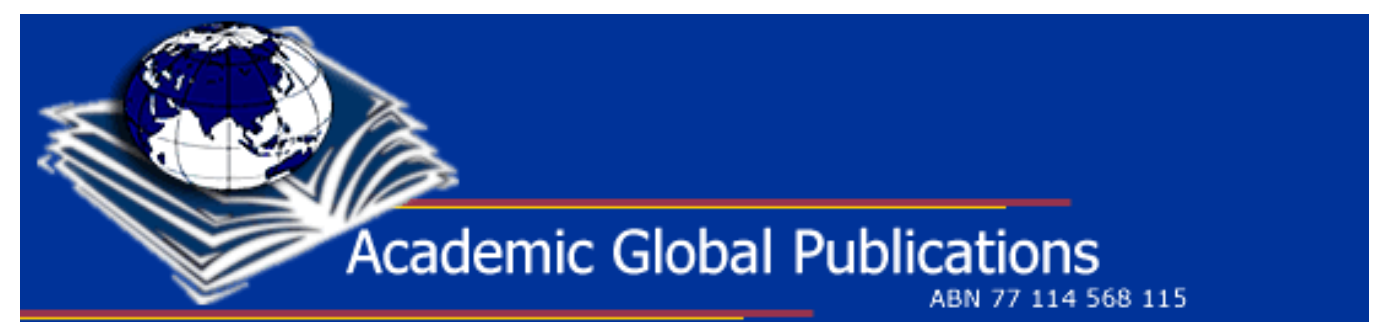

International Technology Management Review

Volume 1 Number 1 (December) 2007

<http://www.academicglobalpublications.com/itmr/>

\title{
Modelling of Supply Chains is the Way Forward
}

The authors:

Maame Ama Aidoo-Sam is a graduate of the Bachelor of Information Technology and Master of Supply Chain Management at Southern Cross University, who has recently worked in supply chain management in a large merchant bank and with an international financial consulting company.

Keith Sloan is an Associate Professor and Director of the World Supply Research Institute at Southern Cross University. He also serves as a Director on Boards of companies operating in electronics equipment manufacturing and distribution.

\section{Contact details:}

keith.sloan@scu.edu.au.

Phone: +61 (2) 66303094

School of Commerce and Management

Southern Cross University

PO Box 157, Lismore, NSW, Australia, 2480 


\section{Abstract}

\section{Title: Modelling of Supply Chains is the Way Forward}

Keywords: Supply chain, modelling, performance management,

Category of paper: Practice paper

Purpose of the research/paper: To demonstrate that modelling of the supply network can be a useful tool for managers

Implications for practice: Sensitive modelling of the supply network using readily available validated modelling approaches can provide insights which enable improved management of supply networks

Value of the paper: The paper will be of interest to academics, practitioners, managers, and/or students of business and management.

Number of pages: 11

Number of tables/figures: 2

Section headings: Introduction, Value of modelling, Factors captured in models, Factors in framing models, Criteria in developing models for a particular organisation, The use of models in policy and competition decisions, Conclusion.

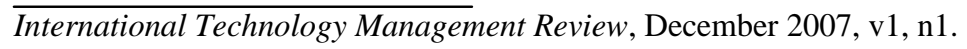




\section{Introduction}

Supply chain management (SCM) has recently moved to the fore of many business activities. What was once an operational part of most organisations is now a strategic part. Many organisations now focus on their supply chains to enable them to become more competitive.

Supply chain management is defined by Simchi-Levi et. al. (2004), as a set of approaches used to efficiently integrate suppliers, manufacturers, warehouses and stores so that merchandise is produced and distributed in the right quantities, to the right locations, and at the right time in order to minimize system-wide costs while satisfying service-level requirements. Supply Networks (SN) are defined as a collections of firms that maintain local autonomy and decision-making capability, but who interact with other firms to fulfil customer requirements by transforming raw materials into finished goods (Simchi-Levi et al., 2000). It needs to be recognised that current supply systems resemble networks rather than chains, reflecting the complex nature of relationships between suppliers, manufacturers, warehouses and customers.

Supply chain modelling has traditionally been seen as belonging to the theoretical realm of the academic; this paper however examines the purpose and value of network modelling for supply managers. Factors to be considered and captured when framing supply network models, and criteria used in developing models for particular organisations are discussed and appraised. Management decisions that can benefit from the use of these models are examined and lessons for supply managers are identified.

\section{Value of modelling}

Managers use models to describe, analyse and improve the supply chain (Wondergem, 2001). Models promote understanding, facilitate focus on key features and attributes and allow performance to be measured. Using models, companies can make better-informed decisions, reduce risk, and save costs. Modelling mimics reality and allows every area of the supply chain to be examined; problem areas become easy to identify.

An example of a network model is the Supply Chain Operations Reference Model (SCOR) developed by the Supply Chain Council (Supply Chain Council, 2006). This is used to

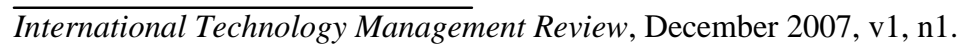


describe and evaluate supply performance across five dimensions: reliability, responsiveness, flexibility, cost and efficiency in asset utilisation (see Appendix 1). The model makes it easier to identify areas in each dimension that need improving and the organisation can better see what is going wrong. The model provides feedback, allowing organisations to identify necessary changes to current processes and procedures. The SCOR model is process driven (see Appendix 2) which makes it relatively easy to implement. Different components of a supply chain may require different models, because the competitive advantage being sought in each area of the supply chain is different. For example, in information management the focus may be on information sharing across supply networks; in procurement the emphasis may be on selecting the best supplier, whereas in logistics attention may be given to reducing delivery times and damage claims. Beneficial changes flowing from modelling the supply chain are numerous and most are likely to result in realisation of improved value-add. Obvious benefits to be gained include reduced costs, better quality products and reduced inventory levels. Others like increased customer satisfaction, better relationships with suppliers and making better-informed decisions, are harder to measure.

\section{Factors captured in models}

Irrespective of the supply area being modelled, every model must first capture the objective(s) for modelling. Once the objective is identified, additional factors can be considered: the current process, problem areas, evaluation techniques, ongoing discussions and performance measures. Based on the competitive advantage that the organisation wants to achieve, the focus may be on quality, cost, reducing inventory, reducing lead times, improving supplier collaboration or customer management.

Appraisal of an organisation's supply chain with new and purpose-built models can provide dramatic breakthroughs in supply chain design and operation. An example is the British Petroleum (BP) case study in Thrower \& Caddell (2000) where a new model was devised to bring the Andrew oil field project into production. BP owned an oilfield in the North Sea (The Andrews Field), which due to geology and logistical problems appeared too challenging to develop. A facilities management group was contracted and they introduced a new model that focussed on business processes. The model it replaced had focussed on business functions and was task oriented. The new model ensured that the right person undertook every job, not necessarily the person who had traditionally been responsible for it. Resource pooling was 
encouraged resulting in reduced downtime and maximised utilisation of resources. The benefits of this model included cost reduction, improvement in service to clients, a strategic facilities management focus and reduction of total management input. To achieve this, first the project was defined and objectives were set, namely getting the Andrews Field off the ground and making it successful. A team was created, suppliers were selected based on ability to meet project needs, and continuous improvement was encouraged with ongoing monitoring.

\section{Factors in framing models}

Because of changes in the business climate, businesses are reinventing their business models (Allen et al., 2001). More emphasis is now placed on value add and business models must factor this in. The information captured by any supply network model depends on the area being modelled. For example, Lambert et al (1999) describe a model for logistics partnership where three major elements are considered: 'drivers' which are compelling reasons to partner; 'facilitators' which provide a supportive environment for growth and maintenance of a relationship; and 'management components' which are joint activities and processes used to build and sustain partnerships. By way of comparison, Prasad and Tata (2000) in modelling an information management system placed emphasis on cost connected with design methodology, competitor action, and training and hardware. Although there are differences in specifics, most models have primarily the same concerns. Whether the model is used in distribution, production, transport or information technology, the main issues considered when framing it will include costs, management approval, defined objectives, expectations and measurable deliverables.

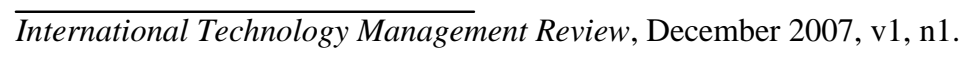




\section{Criteria in developing models for a particular organisation}

Consider an investment bank as an example for selecting criteria in supply chain modelling. In an investment bank, the supply chain manager interacts with different organisations. These include catering, airlines, cleaning, IT services and IT contractors among others. Most of the suppliers used are in service industries. Developing a supply network model for an investment bank is difficult because the number of suppliers is large and most current models are geared towards manufacturing industry. Each supplier also offers a different kind of service; no two services are quite the same. The best way to create a supply network model in this situation is to have a generic model that can be adapted to each different situation. Important criteria to be considered in the generic case include management approval, clearly defined objectives, expected outcomes, cost and on-going performance review. Without management approval any modelling project will not be successful. Clearly defined objectives and expected outcomes make it easier to sell the idea to colleagues and superiors. It is also important to know how much it will cost to get the modelling project off the ground. As most modelling projects are long term, introducing regular performance reviews into the modelling process is important because it allows stakeholders to know which area(s) is working perfectly and ensures problem areas are easily identified.

\section{The use of models in policy and competition decisions}

Modelling can highlight problems with current ways of doing things in a company. It may also show that the current way is good but still identify ways of improving the system. It may show that an organisation needs to collaborate with its suppliers, or even its competitors, to ensure that they help each other to become the best in their industry. Forming strategic alliances with competitors and suppliers, outsourcing logistics to a third party supplier, changing the process of selecting suppliers, focusing on customer requirements or installing an EDI system - these can all be outcomes of modelling the supply network. Each of the above can mean a change in policy and decision making for an organisation.

Companies need to ensure that whatever the outcome of modelling, the policy change that ensues is beneficial for all stakeholders in their supply chains. The objectives for changing a current procedure must be clearly defined and explained to all stakeholders.

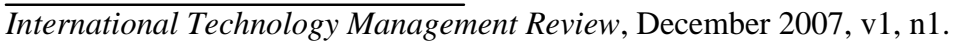




\section{Conclusion}

The success or failure of supply network modelling for an organisation depends a lot on management approval and support. There is no one standard supply network model for the supply chain. Thus supply chain managers must choose the model that best fits their purposes. There are numerous advantages to using network models in particular areas of the supply chain; these include accessing lower costs, better quality products, efficiency in the entire supply chain, customer satisfaction, better relationships with suppliers and better lead times. Models can facilitate the decision making process for supply managers, and allow them to make optimal decisions for their organisations. When new policies are being formulated on the outcomes of modelling, supply managers must determine how such changes will affect suppliers. If supply network models are not utilised properly they may fail, in which case money may be lost and staff morale reduced. In supply network modelling there are many trade offs that the supply manager must be aware of. These include, amongst others, cost versus profits and change versus competitive advantage. All such factors must be considered

by supply managers when deciding on supply network models. Modelling is a good tool when it is used right!

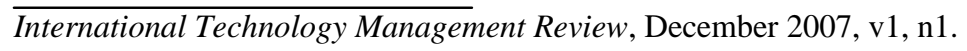




\section{Appendix 1}

Table I: Performance Attributes and Level I Metrics

\begin{tabular}{|c|c|c|}
\hline Performance Attribute & Performance Attribute Definition & Level I Metric \\
\hline \multirow{5}{*}{$\begin{array}{l}\text { Supply chain delivery } \\
\text { reliability }\end{array}$} & \multirow{5}{*}{$\begin{array}{l}\text { The performance of the supply chain in delivering - } \\
\text { the correct product, to the correct place, at the correct } \\
\text { time, in the correct condition and packaging, in the correct } \\
\text { quantity, with the correct documentation, to the correct } \\
\text { customer. }\end{array}$} & Delivery performance \\
\hline & & Fill rates \\
\hline & & \\
\hline & & Perfect order \\
\hline & & fulfilment \\
\hline \multirow[t]{2}{*}{ Supply chain responsiveness } & The velocity at which a supply chain provides & Order fulfilment lead \\
\hline & products to the customer. & times \\
\hline \multirow{4}{*}{ Supply chain flexibility } & \multirow{4}{*}{$\begin{array}{l}\text { The agility of a supply chain in responding to } \\
\text { marketplace changes to gain or maintain } \\
\text { competitive advantage. }\end{array}$} & Supply chain \\
\hline & & response time \\
\hline & & Production \\
\hline & & Flexibility \\
\hline \multirow[t]{6}{*}{ Supply chain costs } & \multirow{6}{*}{$\begin{array}{l}\text { The costs associated with operating the } \\
\text { supply chain. }\end{array}$} & Cost of goods sold \\
\hline & & Total supply chain \\
\hline & & management costs \\
\hline & & Value-added productivity \\
\hline & & Warranty/returns \\
\hline & & processing costs \\
\hline \multirow{3}{*}{$\begin{array}{l}\text { Supply chain asset } \\
\text { management efficiency }\end{array}$} & \multirow{3}{*}{$\begin{array}{l}\text { The effectiveness of an organisation in managing assets } \\
\text { to support demand satisfaction. This includes the } \\
\text { management of all assets - fixed and working capital. }\end{array}$} & Cash-to-cash cycle time \\
\hline & & Inventory days of supply \\
\hline & & Asset turns \\
\hline
\end{tabular}

Source: Wondergem, (2001, p28).

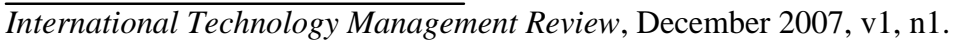




\section{Appendix 2}

\section{Scope of SCOR Processes}
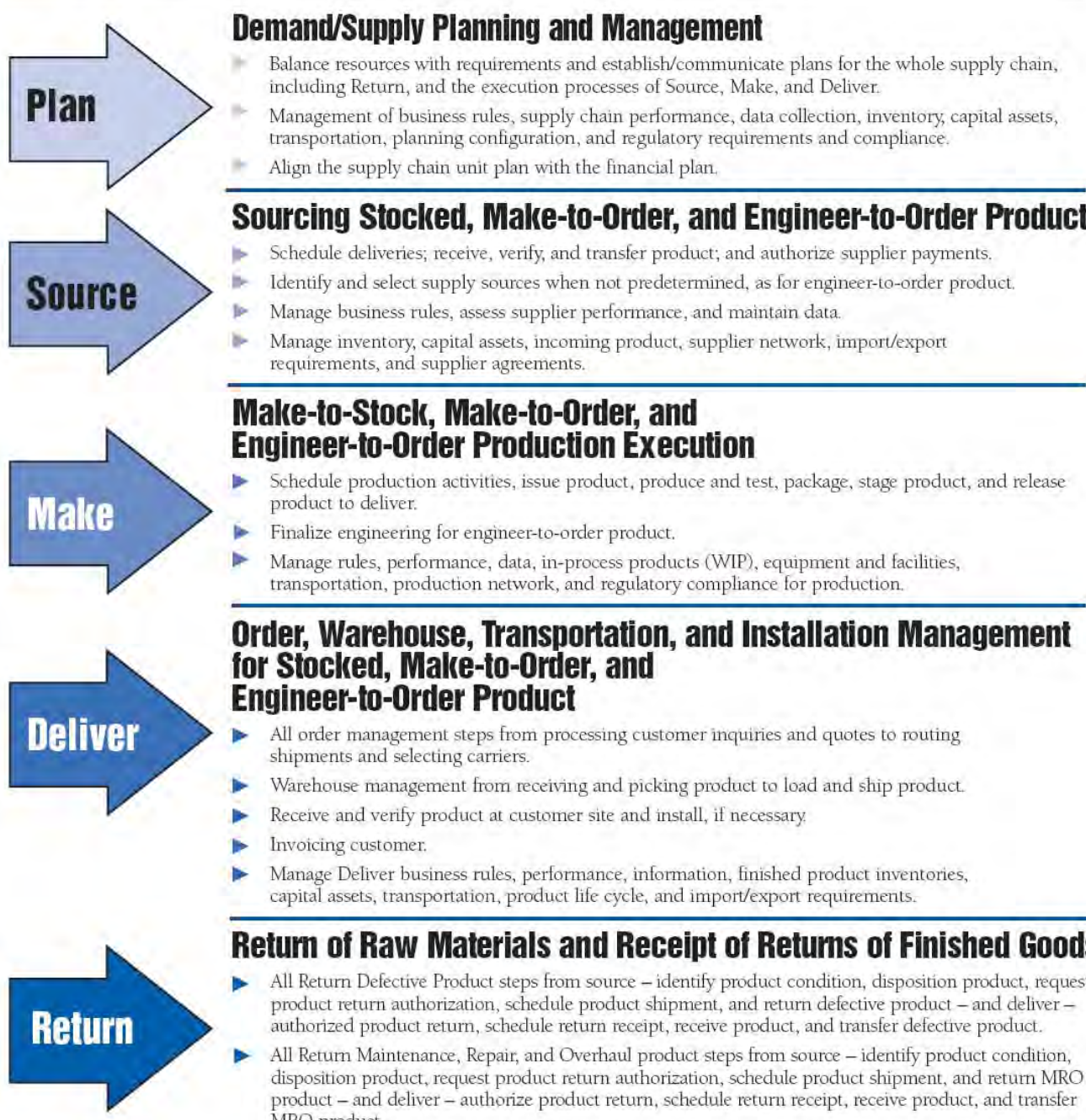

Return of Raw Materials and Receipt of Returns of Finished Goods

- All Return Defective Product steps from source - identify product condition, disposition product, request product return authorization, schedule product shipment, and return defective product - and deliver authorized product return, schedule return receipt, receive product, and transfer defective product.

- All Retum Maintenance, Repair, and Overhaul product steps from source - identify product condition, disposition product, request product return authorization, schedule product shipment, and return MRO product - and deliver - authorize product return, schedule return receipt, receive product, and transfer MRO product.

All Return Excess Product steps from source - identify product condition, disposition product, request product return authorization, schedule product shipment, and return excess product - and deliver authorize product return, schedule return receipt, receive product, and transfer excess product.

- Manage Return business rules, performance, data collection, return inventory, capital assets, transportation, network configuration, and regulatory requirements and compliance.

Source :Supply Chain Council, (2006, p4)

International Technology Management Review, December 2007, v1, n1. 


\section{References}

Allan, B., Mishra, S.B. \& Polevoy, D. 2001, 'The Impact of the Internet on Business Strategies and Opportunities in e-Procurement', European Purchasing and Supply Chain Strategies, May, pp.64 - 67.

Oxford English Dictionary, 2006, [Online], Available: http//oedonline.com, [Accessed 19 February 2006].

Lambert, D.M, Emmelhainz, M.A. \& Gardner, J.T. 1999, 'Building successful partnerships’, Journal of Business Logistics, vol. 20, no. 1.

Pathak, S. 2005, 'An investigative framework for studying the growth and evolution of complex supply networks', PhD thesis, Graduate School of Vanderbilt University.

Prasad, S. \& Tata, J. 2000, 'Information investment in supply chain management', Logistics Information Management, vol. 13, no. 1, pp.33-38.

Simchi-Levi, D., Kaminsky, P. \& Simchi-Levi, E. 2004, 'Managing Supply Chains', Irwin/McGraw-Hill, Boston.

Simchi-Levi, D., Kaminsky, P. \& Simchi-Levi, E. 2000, 'Designing and Managing the Supply Chains: concepts, strategies and case studies', Irwin/McGraw-Hill, Boston.

Supply Chain Council. 2006, "Suply-Chain Operations Reference Model - SCOR Overview Version 8.0" at http://www.supplychain.org/page.ww?section $=S C O R+$ Model $\&$ name $=S C O R+$ Model Accessed $18^{\text {th }}$ September 2007.

Thrower, M. \& Caddell, S. 2000, 'The Integrated supply network: Taking the concept of partnerships one step further', The British Journal of Administrative Managment, July/August.

Wondergem, J. 2001, 'Supply chain operations reference-model includes all elements of demand satisfaction' in Global Purchasing and Supply Chain Strategies, October.

(C) 2006 Academic Global Publications P/L. This work is copyright. You may download and print only one paper copy from this electronic file for your personal use only, from which you may not make any further paper copies.

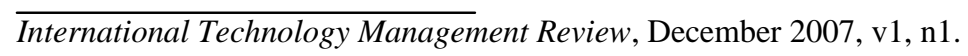

